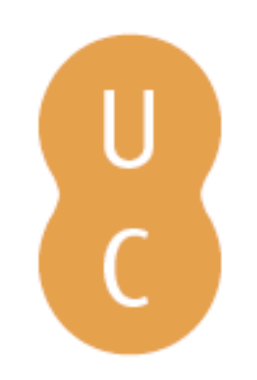

\title{
nommalina
}

\section{Republicanismo e maçonaria na Itália unida: Giuseppe Mazzini, Giuseppe Mazzoni e} Adriano Lemmi

\author{
Autor(es): Conti, Fulvio
}

Publicado por: Imprensa da Universidade de Coimbra

URL

persistente: URI:http://hdl.handle.net/10316.2/31149

DOI: $\quad$ DOI:http://dx.doi.org/10.14195/978-989-26-0497-8_16

Accessed : $\quad$ 26-Apr-2023 12:59:53

A navegação consulta e descarregamento dos títulos inseridos nas Bibliotecas Digitais UC Digitalis, UC Pombalina e UC Impactum, pressupõem a aceitação plena e sem reservas dos Termos e Condições de Uso destas Bibliotecas Digitais, disponíveis em https://digitalis.uc.pt/pt-pt/termos.

Conforme exposto nos referidos Termos e Condições de Uso, o descarregamento de títulos de acesso restrito requer uma licença válida de autorização devendo o utilizador aceder ao(s) documento(s) a partir de um endereço de IP da instituição detentora da supramencionada licença.

Ao utilizador é apenas permitido o descarregamento para uso pessoal, pelo que o emprego do(s) título(s) descarregado(s) para outro fim, designadamente comercial, carece de autorização do respetivo autor ou editor da obra.

Na medida em que todas as obras da UC Digitalis se encontram protegidas pelo Código do Direito de Autor e Direitos Conexos e demais legislação aplicável, toda a cópia, parcial ou total, deste documento, nos casos em que é legalmente admitida, deverá conter ou fazer-se acompanhar por este aviso.

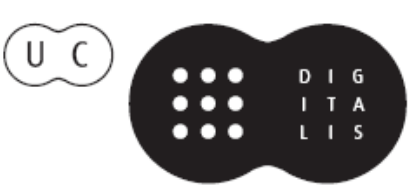


Armando Malheiro da Silva

Maria Luiza Tucci Carneiro

Stefano Salmi

Coordenação

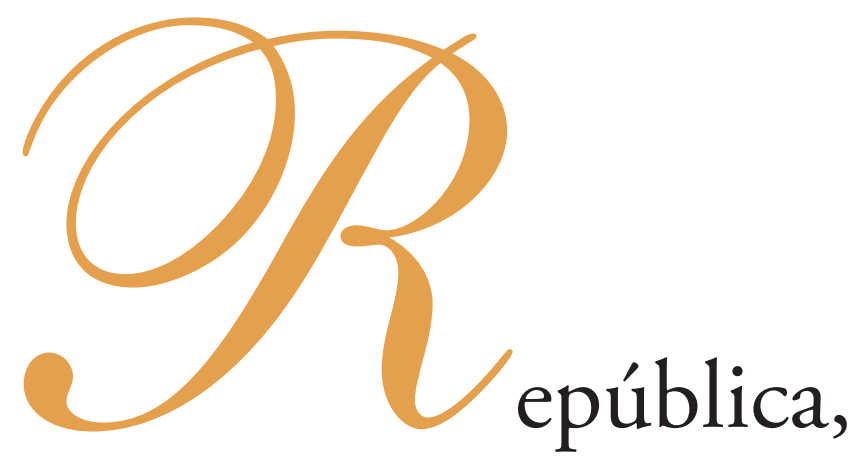

Republicanismo

e Republicanos

Brasil • Portugal • Itália 


\section{Fulvio Conti}

\section{REPUBLICANISMO E MAÇONARIA NA ITÁLIA UNIDA: GIUSEPPE MAZZINI, GIUSEPPE MAZZONI E ADRIANO LEMMI}

1. Maçonaria e política na Itália liberal

Depois de ter se tornado substancialmente estranha ao Ressurgimento por ter sido banida em todos os estados pré-unitários e perseguida pela polícia, a Maçonaria renasceu na Itália no final de 1859, após o longo parêntesis da Restauração, quando um grupo de liberais de inspiração cavouriana fundou o Grande Oriente Italiano (GOI) em Turim. Sua intenção de criar uma estrutura associativa com finalidades essencialmente políticas, que se resumia na vontade de sustentar o Estado unitário que estava se constituindo sob a liderança piemontesa e favorecer a afirmação de um liberalismo laico moderadamente progressista era evidente. Poucos meses depois, surgiu em Palermo outra Obediência, o Supremo Conselho do Rito Escocês Antigo e Aceito, que se tornou o local de reunião das lojas de tendência democrática e republicana, em sua maioria localizadas nas regiões meridionais. Dividas na escolha do rito simbólico para a de Turim, transferida para Florença e depois para Roma logo após mudança da capital, escocesa para a de Palermo - as duas comunidades maçônicas refletiam a cisão existente depois de 1860 entre as duas correntes do Ressurgimento italiano: a moderada e dinástica, que saiu vencedora ao final das lutas pela independência nacional, e a mazziniana, derrotada e insatisfeita, e 
por isso voltada para o objetivo de uma transformação em senso democrático-republicano do Estado sabaudo ${ }^{553}$.

Já por volta da metade dos anos 1860, todavia, a componente democrática e liberal-progressista conseguiu assumir o controle do Grande Oriente, impondo como grão-mestre Giuseppe Garibaldi e criando as premissas para a reunificação das duas Obediências, que aconteceu em 1872 por iniciativa de Giuseppe Mazzoni e de Federico Campanella, respectivamente na liderança do GOI e do núcleo siciliano. A partir desse momento, a maior parte da Maçonaria italiana identificou-se com as posições da chamada esquerda constitucional, que chegou ao poder em 1876 e, por sua vez, estava dividida em grupos regionais de tendências mais ou menos avançadas. Pertenceram à ordem dos pedreiros-livres Presidentes do Conselho como Agostino Depretis, Francesco Crispi, Giuseppe Zanardelli, Alessandro Fortis, Paolo Boselli, e Ministros como Giovanni Nicotera, Ferdinando Martini, Michele Coppino, Guido Baccelli, para nos limitarmos apenas a alguns nomes entre os mais significativos. No entanto, não faltou um grupo de mais acentuada orientação democrática, que atuou tanto na linha radical, isto é, daquela que podemos definir extrema esquerda parlamentar, cujo expoente mais conhecido foi Agostino Bertani, quanto, em menor medida, na oposição republicana e socialista (basta pensar em Ernesto Nathan e Ettore Ferrari, ambos ocuparam o cargo de grão-mestre, ou em Andrea Costa, Arturo Labriola e Giovanni Lerda).

Sob o ponto de vista ideológico, o elemento unificador desses diversos segmentos da esquerda italiana foi, antes de tudo, o anticlericalismo, ou melhor, a defesa da característica laica do Estado, que pelo lado radical-republicano significou também a reivindicação da contribuição democrático-popular ao Ressurgimento como mito fundador da Nação, contra qualquer pretensão legitimista de matriz clerical e reacionária ${ }^{554}$. Além disso, o laicismo esteve estreitamente ligado ao mito do progresso e era entendido como instrumento de modernização da sociedade civil, devendo favorecer a difusão das inovações

\footnotetext{
553 Para maiores informações recomendo CONTI, F. - Storia della maçonaria italiana. Dal Risorgimento al fascismo. Bolonha: Il Mulino, 2003.

${ }^{554}$ Cfr. CONTI, F. - "La massoneria e il mito del Risorgimento". In Il Risorgimento, LII (2000), n. 3, pp. 503-519, agora também in Idem - Massoneria e religioni civili. Cultura laica e liturgie politiche fra XVIII e XX secolo. Bolonha: Il Mulino, 2008, pp. 167-185.
} 
científicas e tecnológicas e uma renovação dos costumes e dos estilos de vida sob a insígnia de uma maior liberdade do indivíduo (escola laica gratuita e obrigatória ${ }^{555}$, casamentos e funerais civis, divórcio, cremação ${ }^{556}$, etc.). Todos os irmãos comungavam de um pacifismo concebido como moderna decadência dos valores cosmopolitas e universais das origens, coisa que não impediu a maior parte deles de cultivar um robusto sentimento patriótico, que no final das contas, ao final da era de Giolitti, seria convertido em aberto nacionalismo ${ }^{557}$.

Este foi, em última análise, um dos princípios que inspiraram o modo de agir maçônico: a substancial identificação da Maçonaria italiana com as instituições liberais, ou melhor, com o Estado unitário nascido das lutas do Ressurgimento. Nenhum dirigente de destaque, mesmo na fase mais aguda da crise de fim de século, nunca colocou em discussão a organização institucional vigente e as orientações de base da política nacional. Os mais entusiasmados protestos levantados contra as medidas contra a liberdade de Pelloux ficaram limitados a algumas lojas e até o pedido, apoiado por expoentes republicanos, de convocar uma assembleia constituinte obteve apenas um fraco eco dentro da família maçônica. O interesse de fornecer legitimidade ao Estado, tanto no plano interno quanto no internacional, foi sempre considerado um empenho prioritário da maçonaria italiana, que desde o início dos anos 1860, por exemplo, chamou os cidadãos às urnas, combatendo contra o abstencionismo de parte católica e de parte mazziniana ${ }^{55}$.

555 Cfr. CONTI, F. - "Massoneria, scuola e questione educativa nell'Italia liberale". In Annali di storia dell'educazione e delle istituzioni scolastiche, XI (2004), pp. 11-27, agora também em Idem, Massoneria e religioni civili, op. cit., pp. 75-99.

${ }^{556}$ Cfr. CONTI, F.; ISASTIA, A.M.; TAROZZI, F. - La morte laica, I, Storia della cremazione in Italia (1880-1920). Turim: Paravia-Scriptorium, 1998.

557 Cfr. CONTI, F. - "De Genève à la Piave. La franc-maçonnerie italienne et le pacifisme démocratique, 1867-1915”. In PETRICIOLI, M.; ANTEGHINI, A.; CHERUBINI, D.; BERNE, Peter Lang (orgs.) - Les Etats-Unis d'Europe. Un project pacifiste. 2004, pp. 213-240, agora também em Idem, Massoneria e religioni civili, op. cit., pp. 101-131.

${ }^{558}$ Cfr. CONTI, F. - "Les liturgies de la patrie. Franc-maçonnerie et identité nationale dans l'Italie unie". In Les francs-maçons dans la cité. Les cultures politiques de la Franc-maçonnerie en Europe, $X I X^{n}-X X^{k}$ siècle, sous la direction de L.P. Martin, Rennes: Presses Universitaires de Rennes, 2000, pp. 77-96; Idem - "Pratiques politiques et franc-maçonnerie au xx" siècle en Italie". In Franc-maçonnerie et histoire: bilan et perspectives. Actes du Colloque international (Rouen, 14-16 Novembre 2001), sous la direction de C. Gaudin et E. Saunier. Rouen: Publications des Universités de Rouen et du Havre, 2003, pp. 223-241; Idem - "Laïcité et légitimation de l'État dans l'Italie libérale: le rôle de la Franc-maçonnerie". In Institutions E représentations du politique. Espagne - France, Italie, XVIIE-XXE siècles, sous la direction de Patrick Fournier, Jean-Philippe Luis, Luis P. Martin et Navidad Planas, 
Além disso, quase nunca, mesmo em suas facções mais extremas, a Maçonaria contestou a legitimidade do instituto monárquico. E quando em Julho de 1900, a crise de fim de século sofreu um último golpe com o assassinato de Umberto I, o Grande Oriente da Itália não hesitou em condenar o cruel delito, "um delito - escreveu Nathan em um cartaz afixado em todas as principais cidades italianas - que em sua selvagem impotência, calunia e suja de lama o nome da Pátria diante do mundo" ${ }^{59}$.

Convém tomar a reação a este episódio para identificar alguns elementos iniciais, através dos quais definir a fisionomia política da Maçonaria italiana no começo do século Xx. Nathan aproveitou a ocasião para pressagiar o retorno a um contexto de maior liberdade e Democracia que banisse as formas de repressão violenta e privilegiasse o aspecto educativo. Mas além desse apelo genérico para recuperar as raízes liberais do Estado, o acontecimento ofereceu-lhe a oportunidade de destacar mais uma vez dois dos eixos em torno dos quais girava o empenho político dos maçons. Patriotismo e fidelidade às instituições monárquicas: estes eram princípios transversais aos alinhamentos políticos e algumas vezes estavam em aberta contradição com algumas filiações partidárias que então reuniam boa parte dos irmãos de Palazzo Giustiniani. O fato de reconhecê-los não é pouca coisa, visto que a Maçonaria professava, pelo menos oficialmente, uma ideologia universalista e tinha internamente muitos expoentes de extrema esquerda contrários à Monarquia ou até preconceituosamente hostis a lógicas nacionalistas. Evidentemente, as lojas e as congregações maçônicas superiores configuravam-se como câmera de compensação das diversas tendências ideológicas e como local de mediação e compromisso, onde o sentimento patriótico ainda representava o fator de adesão de uma geração que crescera no culto das glórias nacionais. Também não se deve esquecer que, pela peculiaridade da história italiana, o nacionalismo e a glorificação das memórias ressurgimentais constituíam, em chave maçônica, o outro lado do laicismo e do anticlericalismo. Defender a Nação nascida do Ressurgimento e a Monarquia sabauda significava também se opor a quem ainda contestava uma e outra, isto é, a Igreja e o movimento católico.

Clermont-Ferrand: Presses Universitaires Blaise Pascal, 2006, pp. 199-207. Para um panorama da produção historiográfica recente cfr. Idem, "La maçonaria". In Nuova informazione bibliografica, IV (2007), n. 1, pp. 83-97.

559 O documento está citado in CONTI, F. - Storia della maçonaria italiana, op. cit., p. 163. 
Por outro lado, analogamente ao que acontece na França e na Espanha, também na Itália no início do século xx, a Maçonaria sofreu uma reviravolta decisiva em termos de Democracia, à qual correspondeu um gradual rebaixamento de extração social de seus membros, agora pertencentes, em sua maioria, à classe média trabalhadora. O artífice da reviravolta foi Ettore Ferrari, grão-mestre de 1904 a 1917, expoente da ala legalista do Partido Republicano e já deputado nos anos 1880, que por causa de seu posicionamento conseguiu recompor as dissidências de um grupo de lojas de tendência radical que saíra do GOI em 1896 e fundara uma Obediência autônoma. A Assembleia Constituinte de 1906, eliminando definitivamente o agnosticismo imposto pelos antigos landmarks maçônicos, modificou diretamente as constituições dos GOI inserindo a afirmação de que estes defendiam "o princípio democrático na ordem política e social". A postura adotada a seguir, foi consequência dessa escolha e se traduziu, por exemplo, no explícito apoio oferecido pela Maçonaria às candidaturas progressistas nas eleições políticas e administrativas (a ponto de, em 1914, segundo estimativas confiáveis, contarem-se na Câmara 90 deputados maçons), e no papel decisivo que esta teve na gestação dos blocos populares, administrações de esquerda que se formaram nesses anos em inúmeras cidades italianas e tiveram muitos irmãos ocupando o cargo de prefeito (o exemplo mais conhecido foi de Ernesto Nathan, que liderou o conselho comunal de Roma de 1907 a 1913).

Frequentada por liberais progressistas, republicanos e socialistas (pelo menos até que o Congresso Nacional do Partido Socialista, que teve lugar em Ancona em 1914, declarou incompatível para seus inscritos a filiação à instituição maçônica), a maçonaria italiana do início do século xx esteve próxima principalmente ao Partido Radical, muitos de seus membros ocuparam cargos de direção e vice-versa. E se é preciso afastar o lugar comum, sustentado por certa publicidade clerical da época, que entre as duas instituições houvesse una perfeita identificação — desmentida até por recentes pesquisas sobre a estrutura sociológica e organizativa do Partido - parece indubitável, por outro lado, que do ponto de vista ideológico e político "os objetivos e as estratégias do Partido Radical e da Maçonaria, pelo menos a partir de 1905-06, fossem extraordinariamente semelhantes, para não dizer idênticos"560. A transversalidade da instituição

\footnotetext{
${ }^{560}$ ORSINA, G. - Senza Chiesa, né classe. Il partito radicale nell'età giolittiana. Roma: Carocci, 1998, p. 151.
} 
maçônica e o fato de esta não querer se identificar com uma única formação política, mas ter como projeto configurar-se como local de encontro e mediação entre as diversas correntes de esquerda, foi posteriormente confirmado pelo fato de que naqueles mesmos anos esta procurou promover um novo Partido, o Partido Democrático Constitucional, que deveria reunir a ala mais moderada do liberalismo progressista ${ }^{561}$.

Depois do que dissemos aqui, não é de espantar que, em 1908, a parte mais conservadora da Maçonaria italiana e aquela que pretendia se ligar à tradição anglo-americana promovesse uma cisão, da qual surgiria a Grande Loja da Itália, depois chamada de Piazza del Gesù. A confirmação de que o gradual deslocamento para a esquerda do Grande Oriente havia provocado entre os irmãos uma área de descontentamento e insatisfação que também se manifestou no pedido de um retorno a uma maior atenção para os aspectos rituais, para a dimensão espiritual e de iniciação, em resumo, para uma redescoberta das antigas raízes filosóficas e esotéricas da Maçonaria.

\section{Um grão-mestre que faltou: Giuseppe Mazzini}

Ainda que na história da Maçonaria italiana pós-unitária, como afirmamos, o instinto legitimista tenha sempre prevalecido sobre impulsos políticos particulares dos indivíduos filiados, muitos dos quais pertencem aos blocos da esquerda democrática e socialista, também merece ser destacado que de 1870 até à Primeira Guerra Mundial esta foi liderada ininterruptamente por grão-mestres de firme fé republicana: Giuseppe Mazzoni (1870-1880); Giuseppe Petroni (18801885); Adriano Lemmi (1885-1896); Ernesto Nathan (1896-1904); Ettore Ferrari (1904-1917). Nas páginas seguintes, proporemos um breve perfil de dois desses personagens, os toscanos Giuseppe Mazzoni e Adriano Lemmi, e o papel que eles desempenharam tanto na instituição maçônica quanto na vida pública. Antes, porém, é preciso comentar o interessante caso da frustrada presença

\footnotetext{
${ }^{561}$ Cfr. SCORNAJENGHI, A. - La sinistra mancata. Dal gruppo zanardelliano al Partito Democratico Costituzionale Italiano (1904-1913). Roma: Istituto per la storia del Risorgimento italiano - Archivio Guido Izzi, 2004.
} 
entre os grão-mestres do pai do republicanismo italiano, Giuseppe Mazzini, e da querelle em torno das reais relações que ele teve com a Maçonaria.

Desde o momento de sua morte, em 1872, a Maçonaria italiana procurou disseminar a ideia de que ele tivesse sido um membro efetivo da instituição maçônica. A tentativa de se apropriar da figura de Mazzini não apenas em termos simbólicos, mas também o identificando como autêntico afiliado foi muito explícita em algumas cerimônias públicas que aconteceram em várias cidades italianas em 1872 e especialmente por ocasião dos funerais genoveses de 17 de Março. Um comitê maçônico presidido pelo chefe da mais importante loja de Gênova, a Triunfo Ligure, acompanhou até o cemitério de Staglieno o féretro de Mazzini usando as vestes de mestre pedreiro livre de trigésimo sétimo grau, o último e mais elevado do rito escocês antigo e aceito. A partir daí, a Maçonaria cultivou de várias formas o culto à Mazzini, e a ideia de sua filiação à instituição foi sustentada também pela publicidade católica ${ }^{562}$.

Na realidade, Mazzini nunca foi regularmente filiado a nenhuma loja e, aliás, desde a fundação em 1831 da Giovine Italia, ele tomou nítida distância não apenas da ideologia, mas também da estrutura organizativa e do ritualismo simbólico dos maçons ${ }^{563}$. Mazzini escreveu claramente em uma carta de Outubro de 1831, para Ippolito Benelli:

"Temos visto que a Maçonaria, a Carbonária ou outra sociedade constituída não tem tido êxito, ou não são aceitas pelos homens de 1831: renunciamos, portanto e para sempre, à ideia de nos associarmos a elas! Poderíamos dizer que essas sociedades operam em muitos lugares, é verdade, mas sem um centro real e constante de operação e união; surgiram em um tempo menos adiantado do que o nosso e não correspondem mais às necessidades e às ideias do nosso tempo; tinham hierarquias demais, simbolismo demais - digamos também - impostura. Por que não criamos uma que não tenha esses defeitos, que seja simples, clara, que tenha apenas a forma necessária para ser

562 Para maior aprofundamento cfr. CONTI, F. - "Mazzini massone? Costruzione e fortuna di un mito”. In Memoria e Ricerca, n.s., XIV (2006), n. 21, pp. 157-175, agora também em Idem, Massoneria e religioni civili, op. cit., pp. 187-211.

563 Cfr. PERUTA, F. Della - "La Massoneria in Italia dalla Restaurazione all'Unità". In MOLA, A.A. (org.) - La Massoneria nella storia d'Italia. Roma: Atanòr, 1981, p. 64. 
reconhecida, entendida rapidamente, que não seja mais do que um vínculo de fraternidade, mas forte, determinado, preciso?" ${ }^{24}$.

Mazzini permaneceu fiel a esta linha de pensamento por todo o Ressurgimento, que coincidiu com a substancial decadência organizativa do associacionismo maçônico. E em 1860, quando publicou os Doveri dell'Uomo (Deveres do Homem), ele dedicou todo um capítulo para definir a função da associação e a relação indissolúvel que a ligava à ideia de progresso, do qual se deduzia o nítido repúdio dos vetustos e superados modelos organizacionais sectários, inclusive os da Maçonaria.

"A associação - escrevia Mazzini — deve ser pública. As associações secretas, armas de guerra legítimas onde não há Pátria nem Liberdade, são ilegais e podem ser dissolvidas pela Nação, quando a Liberdade é direito reconhecido, quando a Pátria protege o desenvolvimento e a inviolabilidade de pensamento. Se a associação deve abrir a estrada para o Progresso, deve ser submetida ao exame e ao julgamento de todos" $" 565$.

Na década pós-unitária, como se sabe, Mazzini foi obrigado a não observar os planos iniciados em 1860 e recomeçou a fundar associações secretas (a Falange Sacra, a Aliança Republicana Universal) para conseguir seus objetivos políticos: a finalização da independência nacional e o nascimento da República. Até com relação à Maçonaria, ele adotou um comportamento indulgente, consciente do fato que esta poderia se transformar em um instrumento organizativo muito útil para alcançar seus fins. Ele manteve relações frequentes e cordiais principalmente com o grupo de lojas adeptas ao Supremo Conselho do Rito Escocês de Palermo, a Obediência de características mais claramente democráticas e republicanas, mostrando-se frequentemente pródigo de conselhos e opiniões. Mas teve sempre bem clara a distinção de papéis que devia haver entre as organizações políticas fundadas por ele e o associacionismo maçônico, do qual não

\footnotetext{
${ }^{564}$ Lettera a Ippolito Benelli, [Marsiglia], 8 ottobre [1831]. In MAZZINI, G. - Scritti editi ed inediti. vol. V. Imola: Galeati, 1909, p. 61.

565 Citado da edição crítica MACCHIA, G. (org.) - Doveri dell'Uomo. Roma: Camera dei Deputati, 1972, pp. 107-108.
} 
aprovava os rituais obscuros e barrocos e a ideologia muito vaga, voltada para um humanitarismo genérico privado de perspectivas concretas de ação.

Entre as associações republicanas e as maçônicas, sustentava Mazzini, podiam haver acordos e formas de colaboração, mas nenhuma confusão do ponto de vista organizativo e principalmente nenhuma concessão sob o aspecto da liderança. Tanto mais que as lojas maçônicas acolhiam também indivíduos de diferentes orientações políticas, e não ofereciam, portanto, garantias suficientes para se transformarem nas células de atividade clandestina, necessariamente baseadas na forte coesão ideológica de seus membros, que segundo Mazzini eram indispensáveis para vencer a inércia do governo, completar a unificação da pátria com a libertação de Roma e iniciar a tramitação de fundação da República. Ele manifestava essas dúvidas a Federico Campanella em uma carta de Junho de 1867, na qual escrevia:

"A Maçonaria, aceitando por anos e anos qualquer homem sem levar em conta opiniões políticas, tornou-se absolutamente inútil para qualquer objetivo nacional. Para fazer alguma coisa, seria preciso antes uma medida de eliminação, uma revisão das fileiras, depois uma fórmula nacional ou política para as iniciações. Tudo isto para transformar a Maçonaria em uma Sociedade política como a Aliança Republicana. E isto não conseguirão nem os poucos amigos de Gênova, nem outros"s66.

No entanto, escrevia a outro seu fiel discípulo, Maurizio Quadrio, em 4 de Julho de 1868. "Tento transformar ou comprometer a Maçonaria. É um elemento numérico forte, e inclinado, há algum tempo, a vir para o meu lado. Procuro fazê-la voltar a ser republicana, como já é na Sic[ilia]”567. Quando, porém, dali a alguns dias, o Supremo Conselho de Palermo the propôs suceder Garibaldi no cargo de grão-mestre e lhe enviou um diploma de trigésimo sétimo grau e algumas linhas de uma fórmula de juramento que deveria devolver assinada, ele não hesitou em responder:

\footnotetext{
${ }^{566}$ Carta para Federico Campanella, [Londres], 12 de Junho de [1867]. In MAZZINI, G. - Scritti editi ed inediti. vol. LXXXV. Imola: Galeati, 1940, pp. 89-90.

${ }^{567}$ Carta para Maurizio Quadrio, [Londres], 4 de Julho de [1868]. In MAZZINI, G. - Scritti editi ed inediti. vol. LXXXVII. Imola: Galeati, 1940, p. 118.
} 
"Apesar do conteúdo do juramento que eu deveria assinar estar de acordo com minhas convicções, este juramento contém, não obstante, cláusulas às quais não poderei conscientemente aderir sem reservas. [...] Prestei apenas um juramento em minha vida: foi à República, e gostaria de descer apenas com ele ao sepulcro" ${ }^{168}$.

Em 20 de Julho de 1868, a liderança da Obediência maçônica siciliana, por indicação do próprio Mazzini, foi assumida por Federico Campanella, que buscou colocar em prática os ensinamentos do Apóstolo dando à sua direção um forte cunho político. Muito pouco interessado nos aspectos iniciáticos e esotéricos, preocupou-se mais que a Obediência dirigida por ele tivesse uma nítida orientação democrática e antimonárquica, e em alguns casos não hesitou em favorecer superposições organizativas entre as lojas maçônicas e as associações republicanas. Ele promoveu a grande assembleia constituinte que aconteceu em Roma em 1872 e marcou a confluência do Supremo Conselho de Palermo e outros grupos maçônicos dissidentes no Grande Oriente da Itália. Mazzini, falecido em 10 de Março, não pode ver o êxito dessa iniciativa. Até seus últimos dias de vida informou-se sobre os preparativos e se esforçou para que o projeto desse bom resultado. Apesar de não pertencer à Maçonaria e nunca ter se filiado a ela, havia lucidamente compreendido que esta organização podia representar um papel importante na vida pública do País. Agora que a independência tinha sido alcançada e a bandeira tricolor tremulava no palácio do Quirinal, as lojas maçônicas podiam continuar a ser um lugar de agregação das forças democráticas e progressistas da península, e serem promotoras do processo de modernização e democratização que esta necessitava.

A herança de Mazzini foi usada por numerosos seguidores que foram ao mesmo tempo republicanos e maçons. Se nas últimas décadas do século XIX a memória de seu pensamento e sua obra não se perderam, muito foi devido ao culto e à devoção que lhe reservou o universo maçônico.

${ }^{568}$ A carta, datada de 9 de Julho de 1868, está em MAZZINI, G. - Scritti editi ed inediti. vol. LXXXVII. op. cit., p. 124. 


\section{Giuseppe Mazzoni: entre democracia e socialismo}

A constituinte romana de 1872, que deu ao Grande Oriente da Itália uma base organizativa mais sólida e uma penetração realmente nacional, confirmou no cargo de grão-mestre Giuseppe Mazzoni5 ${ }^{69}$. Eleito deputado em 1870, Mazzoni era um advogado de comprovada tendência democrática, desenvolvida desde a juventude dentro do núcleo familiar. O pai, de fato, compartilhara os ideais jacobinos e, em 1799, quando era maire da cidade de Prato, fizera erigir uma árvore da liberdade. Aproximando-se das ideias de Mazzini, Mazzoni logo começou a fazer parte dos encontros culturais e políticos, que se empenhavam, em Prato, em difundir as ideias liberais e promover iniciativas humanitárias e filantrópicas. Convencido de não poder - são palavras dele — "surgir um povo livre e independente da cabeça dos príncipes", em 1847, viu com grande desconfiança o movimento reformador iniciado por Pio IX. Apesar disso, uma vez promulgada pelo grão-duque da Toscana a lei que introduzia uma limitada liberdade de imprensa, Mazzoni, em Junho de 1847, esteve entre os fundadores, em Florença, do jornal L'Alba, de cujas colunas sustentou ideais democráticos e patrióticos. Em de 22 de Março de 1848, com a deflagração da primeira guerra da independência, alistou-se na coluna de voluntários que, partindo da Toscana para a Lombardia, acabaram se dirigindo para Módena, pois a cidade havia se rebelado contra o duque Francesco V e onde Mazzoni esforçou-se em vão pela instauração de um governo republicano.

Voltando para Prato, tornou-se promotor do Círculo do Povo, que reuniu os democratas de orientação republicana e elaborou um programa político muito avançado, em que figuravam o pedido do sufrágio universal, da liberdade de palavra e de associação, de vastas autonomias municipais e de um conjunto de reformas sociais destinadas a resolver os problemas de trabalho e melhorar as

\footnotetext{
${ }^{569}$ Retomando aqui as grandes linhas do verbete "Giuseppe Mazzoni" que escrevi para o Dizionario biografico degli italiani. vol. 72. Roma: Istituto della Enciclopedia Italiana, 2009. Neste dicionário encontramos Giuseppe Mazzoni. Cenni biografici. Roma: Tip. Capaccini, 1880; PAOLINI,P. - "Documenti relativi all'esilio in terra di Francia di Giuseppe Mazzoni e Atto Vannucci". In Bollettino storico pistoiese. 1960, pp. 105-110; ADAMI, G. - Giuseppe Mazzoni. Un maestro di libertà. Prato: Azienda autonoma di turismo, 1979; CIUFFOLETTI, Z. - "La lotta politica e sociale: l'amministrazione comunale, i partiti politici, i conflitti sociali e di gruppo (1815-1887)". In MORI, G. (org.) - Prato, storia di una città, III. t. 2. Il tempo dell'industria (1815-1943). Firenze: Comune di Prato - Le Monnier, 1988, pp. 1260 ss.; ADILARDI, G. - Memorie di Giuseppe Mazzoni (1808-1880), I, L’uomo, il politico, il massone (1808-1861). Pisa: Pacini, 2008.
} 
condições das classes populares. Com base nesse programa, em Junho de 1848, Mazzoni foi eleito deputado para o Conselho Geral da Toscana, onde lutou para retomar a guerra contra a Áustria e por uma extensão das liberdades estatutárias. Em Outubro de 1848, quando Giuseppe Montanelli foi chamado pelo grão-duque para liderar o governo, Mazzoni obteve a pasta de Anistia e Justiça e das Relações Eclesiásticas.

Depois da saída do grão-duque Leopoldo II de Florença, em 8 de Fevereiro de 1849, e sua decisão de se refugiar em Gaeta (era a véspera da proclamação da República romana), Mazzoni passou a fazer parte, com Montanelli e Guerrazzi, do Governo Provisório que regeu o destino do Estado e, como primeiro ato, convocou para 13 de Março as eleições de uma assembleia constituinte, à qual delegou a eventual proclamação da República. Quando a assembleia se instalou, em 25 de Março de 1849, o triunvirato devolveu seu mandato para a Constituinte, que concedeu poderes extraordinários apenas para Guerrazzi. Este, no entanto, contrariamente ao desejo popular e aos propósitos de Montanelli e Mazzoni, negou-se a proclamar a República e ligar seu destino ao da República romana. De resto, poucos dias depois, em 12 de Abril de 1849, o exército austríaco atravessava os Apeninos e reintegrava no trono Leopoldo II.

Para Giuseppe Mazzoni, abriu-se inevitavelmente a estrada do exílio político: conseguindo fugir das buscas policiais, refugiou-se em Marselha, onde foi iniciado na Maçonaria, e de lá em Paris. Membro ativo da grande comunidade de patriotas italianos refugiados na França, ele tomou parte no debate sobre o insucesso dos movimentos revolucionários de 1848 e da primeira guerra da independência. Em um primeiro momento, até o golpe de Estado de 2 de Dezembro de 1851, que de fato pôs fim à experiência republicana francesa e às esperanças de todos que observavam Paris para recomeçar a revolução na Europa, participou ativamente também de planos para dar uma organização mais estável ao movimento patriótico italiano. Depois, especialmente após o insucesso dos movimentos mazzinianos de 1853, prevaleceu o desânimo e Mazzoni, enquanto se debatia com as dificuldades cotidianas impostas pela experiência de exilado (tornada definitiva pela condenação à prisão perpétua que lhe foi infligida em 1853 pelo processo que aconteceu em Florença contra os membros do deposto Governo Provisório), não economizou críticas contra ninguém, a começar 
justamente por Mazzini, obstinava-se a promover agitações insurrecionais destinados inevitavelmente a terminar em derrota.

Nos anos que passou na França, Mazzoni foi aperfeiçoando sua concepção de Democracia e, nesse sentido, foi-lhe muito útil a amizade que conseguiu estreitar com Lamennais e Proudhon. Do primeiro, extraiu importantes motivos de reflexão sobre a liberdade de consciência, o problema das relações entre Estado e Igreja e os direitos invioláveis do cidadão. Com Proudhon, compartilhou a ideia do valor social do trabalho e o consequente empenho para chegar gradualmente, sem choques violentos, a uma sociedade mais igualitária e progressista. Mas, sobretudo, comungou com Proudhon do comportamento antiautoritário e a aversão por qualquer forma de concentração estatal, à qual sempre se opôs, mesmo sem chegar a uma visão completamente federalista, o conceito de um Estado baseado em uma forte autonomia dos poderes locais e mais amplas liberdades individuais.

Mazzoni voltou para a Itália somente depois da revolução pacífica de 27 de Abril de 1859, que assinalou o fim da dinastia dos Lorena na Toscana. Eleito deputado para a Assembleia Nacional, o novo parlamento toscano que iniciou seus trabalhos em Florença em Agosto de 1859, para não trair seus princípios republicanos não compareceu à sessão em que foi votada a anexação da Toscana ao Piemonte sabaudo. Em 1860, Mazzoni esteve ativo na coleta de fundos para a expedição de Garibaldi na Sicília e, no final do ano, esteve entre os fundadores, em Florença, da Fraternidade dos Artesãos, uma associação destinada a ter um importante papel na história do movimento operário italiano. Foi neste cenário, e mais em geral nos percalços das organizações democráticas e republicanas, que o advogado de Prato gastou suas melhores energias nos anos imediatamente posteriores, presidindo o IX Congresso das Sociedades Operárias Italianas que aconteceu em Florença em Setembro de 1861 e criando, sempre em Florença, em Fevereiro de 1862, juntamente com Giuseppe Dolfi e Antonio Martinati, a Sociedade Democrática. Vale a pena ler alguns trechos do programa desta associação, em cuja elaboração Mazzoni trabalhou diretamente e no qual ele se reconheceu plenamente:

"O programa de uma Sociedade que recebe o título de democrática não pode ser outro que o programa da liberdade. Nossa divisa diz liberdade em tudo e para todos, ou em outras palavras, no que diz respeito à ordem moral, não admitimos outra sanção a não ser da consciência, no que diz respeito à ordem 
política, civil e econômica, nenhuma autoridade fora do direito e da Justiça. Para nós não existe governo livre onde não há igualdade de direitos, onde a liberdade em todos os seus atributos não constitui o direito comum's70.

De tendência radical, a Sociedade Democrática Florentina teve como porta-voz o jornal La Nuova Europa, cujo primeiro número apareceu em 14 de Abril de 1861 e se distinguiu, em sua breve, mas batalhadora existência (parou as publicações em Outubro de 1863), pela clamorosa polêmica com Mazzini. Mazzoni e os outros colaboradores do jornal, entre os quais se destacou principalmente Alberto Mario, propuseram, de fato, a "inversão da fórmula" mazziniana "unidade-liberdade", sustentando a necessidade, para o movimento democrático, de antepor à luta pela unidade nacional a batalha pelas reformas civis e políticas e pela descentralização administrativa. Primeiro a liberdade, sem dúvida, e depois a unidade, ou seja, Roma e Veneza.

Com relação a Mario e os outros democratas florentinos, Giuseppe Mazzoni destacava, todavia, uma maior atenção pela questão social. Atenção que se reforçou notavelmente depois de seu encontro com Bakunin, em 1864, quando o revolucionário russo chegou a Florença e identificou exatamente em Mazzoni um dos interlocutores privilegiados para a realização de seus projetos políticos. E, com efeito, o ex-triúnviro de 1849 tornou-se um dos homens de maior destaque das organizações secretas constituídas por Bakunin para tentar obter suas finalidades revolucionárias e subverter a ordem social e política existentes: em 1864, aderiu à Irmandade Internacional, em Novembro de 1868, à Aliança Internacional da Democracia Socialista e em Fevereiro de 1869, à seção de Genebra da Associação Internacional dos Trabalhadores, a chamada Primeira Internacional.

Com o transcorrer dos anos, entretanto, Mazzoni tomou gradualmente distância das posições mais extremas assumidas por Bakunin, não concordando com sua vertente niilista e o acentuado antiestatalismo. Não conseguiram levar adiante uma relação que já estava irremediavelmente deteriorada depois de alguns encontros acontecidos em Prato entre Março e Abril de 1871, justamente nos dias em que se consumava a sangrenta experiência da Comuna de Paris.

${ }^{570}$ ADAMI, G. - Giuseppe Mazzoni. op. cit., p. 248. 
Bakunin teria depois taxado o amigo de modo desprezível como "o Catão da Toscana", como um simples "federalista regional".

Mazzoni, por outro lado, seguindo uma linha política mais moderada, alguns meses depois ocupava um cargo de deputado, para o qual tinha sido eleito por Prato, como já dissemos, em Dezembro de 1870. Confirmado nas eleições de 1874 e de 1876, sentou-se à esquerda na Câmara, mas não se distinguiu por uma presença especialmente ativa nas discussões. Em 17 de Março de 1879, foi nomeado senador e prestou juramento em 17 de Junho. Nos período pós-unitário esteve constantemente presente no Conselho Comunal de Prato e a partir de 1865 no provincial de Florença.

A última década de sua vida foi caracterizada, além da atividade parlamentar, pela militância na Maçonaria, na qual tinha sido iniciado durante o exílio francês. Regularizado em 1869, provavelmente na loja Universo de Florença, em Maio daquele mesmo ano, foi eleito grão-mestre adjunto do Grande Oriente da Itália, a Obediência maçônica que a partir de Setembro de 1870, depois da demissão do grão-mestre Lodovico Frapolli, guiou como regente e da qual foi depois grão-mestre efetivo a partir de 27 de Janeiro de 1871 até sua morte. Entre os atos mais significativos que Mazzoni cumpriu na década em que dirigiu o Grande Oriente pode-se lembrar a transferência da sede para Roma em 1871, a já mencionada fusão com o Supremo Conselho do Rito Escocês de Palermo em 1872, a fundação, em 1877, da loja Propaganda Maçônica, uma loja dirigida diretamente pelo grão-mestre e destinada a acolher os expoentes mais importantes do mundo político, econômico e cultural.

Giuseppe Mazzoni morreu em Prato em 11 de Maio de 1880. Muitas vezes acusado, durante o período em que foi grão-mestre, de ter guiado a Maçonaria com inércia e sem conseguir garantir uma visibilidade adequada na cena pública, com sua morte e com as exéquias fúnebres que se seguiram ele obteve uma clamorosa revanche. Os funerais que se celebraram em Prato de forma rigorosamente civil na tarde de 14 de Maio, ofereceram à Maçonaria uma extraordinária ocasião de abertura para o exterior e demonstração de força. Os notáveis do Grande Oriente acorreram à cidade Toscana com a notícia da agonia do grão-mestre e decidiram unanimemente que todos os membros da Obediência deviam participar do funeral usando suas insígnias e que cada loja exibiria seu estandarte. Sobre o féretro de Mazzoni foram depostas suas insígnias maçônicas, 
a faixa de $33^{\circ}$ grau, o colar do Grande Oriente da Itália e a jóia de fiador da amizade com a Grande Loja da Hungria.

Muito significativa foi a ordem com que foi organizado o cortejo fúnebre, que evidenciou a absoluta preeminência atribuída à Maçonaria no universo político e associativo que Mazzoni representava. Atrás da Sociedade Filarmônica de Prato e dos alunos do Colégio Cicognini, que abriram o cortejo, desfilou o estandarte do grão-mestre, levado pelos irmãos Adolfo Chiossone, Felice Giammarioli e Gaetano Pini, e logo a seguir "quarenta e sete bandeiras maçônicas divididas em duas filas em torno do carro fúnebre". O primeiro dos oito lugares de honra ao redor do féretro foi ocupado pelo grão-mestre adjunto e sucessor designado de Mazzoni, Giuseppe Petroni, ao lado do qual estava Pirro Aporti, grão-mestre adjunto honorário e presidente da Grande Loja do Rito Simbólico. Imediatamente atrás vinham Federico Campanella, Adriano Lemmi, Luigi Castellazzo, Ulisse Bacci, Francesco Curzio, Gherardo Gherardi, Raffaele Jovi, Lodovico Canini e mais de "500 irmãos usando suas ricas e variadas insígnias". Atrás deles — como se lê no relato da cerimônia fúnebre — "vinha outra numerosa multidão de maçons portando um simples raminho de acácia”, seguidos pelo estandarte municipal, pela junta e pelo conselho comunal completos e, mais atrás, pelas representações de instituições, escolas e associações de Prato e outras cidades da Toscana.

"Um povo imenso — reporta a Rivista della maçonaria italiana - que acorreu das cidades vizinhas e dos campos apinhava-se nas praças e ao longo das ruas, tanto que nos pontos mais estreitos o cortejo fúnebre abria passagem com dificuldade e lentamente. A curiosidade em admirar a extraordinária pompa de um funeral quase exclusivamente maçônico, o respeito e a veneração pelo defunto lia-se em todos os rostos" ${ }^{\prime \prime 71}$.

Com efeito, a impressão causada pelas exéquias do grão-mestre foi enorme, assim como seu caráter civil e a participação de muitas centenas de maçons deixaram uma recordação indelével em uma cidade "que nunca tinha visto nada semelhante" ${ }^{572}$. A cidade de Prato, depois, deu o nome do ilustre concidadão

\footnotetext{
571 "Funerali del fratello Giuseppe Mazzoni 33, gran maestro della maçonaria in Italia e nelle colonie italiane". In Rivista della maçonaria italiana, 1880, n. 8-9.

572 SOLDANI, S. - "Vita quotidiana e vita di società in un centro industrioso". In Prato, storia di
} 
a uma parte do Corso e contribuiu para a coleta de fundos para erigir um monumento em sua honra, que foi colocado na Praça do Duomo e inaugurado em 9 de Maio de 1897 com a presença do grão-mestre de então, Ernesto Nathan, e com a participação, mais uma vez, de inúmeros maçons ${ }^{573}$. Mas a história dos restos mortais de Mazzoni, assim como de outros cadáveres ilustres daqueles anos, não se concluiu com a sepultura de Maio de 1880. Nos meses seguintes, o GOI, com a decisiva contribuição financeira de Adriano Lemmi, adquiriu uma porção de terreno no cemitério Verano em Roma para erguer ali um monumento em memória dos grão-mestres da ordem. Este monumento foi inaugurado em 15 de Janeiro de 1885, exatamente com o traslado das cinzas de Mazzoni, cujos espólios mortais, exumados e transportados a Roma, foram incinerados naquele mesmo dia no templo crematório da capital ${ }^{574}$ : uma cerimônia cheia de significados, que representou o ato conclusivo da assembleia constituinte de 1885 e uma nova ocasião para a Maçonaria italiana afirmar seus princípios e exibir sua força diante da opinião pública.

\section{Adriano Lemmi, um grão-mestre entre Mazzini e Crispi}

O sucessor de Mazzoni, como dissemos, foi Giuseppe Petroni, advogado e principalmente antigo conspirador mazziniano, que por sua crença política havia sido condenado primeiro à morte, depois à prisão perpétua pelo governo pontifício, em cujos cárceres haviam passado 17 anos, de 1853 a 1870575. Aproximou-se da Maçonaria em 1871, depois de ser libertado, e começou a assumir um papel diretivo em 1872, quando a constituinte romana elegeu-o membro do conselho

una città, III. t. 2. op. cit., p. 728. Sobre os funerais laicos na Itália liberal cfr. VERUCCI, G. - L'Italia laica prima e dopo l'Unità, 1848-1876. Anticlericalismo, libero pensiero e ateismo nella società italiana. Roma-Bari: Laterza, 1981, pp. 193 ss.; MENGOZZI, D. - La morte e l'immortale. La morte laica da Garibaldi a Costa. Manduria-Bari-Roma: Piero Lacaita Editore, 2001.

${ }^{573}$ Sobre a história do monumento cfr. RICCOMINI, F. - Prato e la maçonaria, 1870-1923. Roma: Atanor, 1988, pp. 50 ss.

${ }^{574}$ Cfr. BACCI, U. - Il libro del massone italiano, II. op. cit., pp. 371-2. Sobre o movimento cremacionista em Roma cfr. ISASTIA, A.M. - "La laicizzazione della morte a Roma: cremazionisti e massoni tra Ottocento e Novecento". In Dimensioni e problemi della ricerca storica, 1998, n. 2, pp. 55-97.

575 Para um perfil do personagem cfr. ISASTIA, A.M. - Uomini e idee della maçonaria. La maçonaria nella storia d'Italia. Roma: Atanor, 2001, pp. 21-52. 
da ordem. A assembleia de 1879 o elegera único grão-mestre adjunto. Esteve no cargo de grão-mestre efetivo de Maio de 1880 a Janeiro de 1885, quando assembleia constituinte maçônica de Roma elegeu-o para seu lugar Adriano Lemmi.

Nascido em Livorno, em 30 de Abril de 1822, desde muito jovem teve grande fascínio pelas ideias de Mazzini e foi perseguido pela polícia do grão-duque ${ }^{576}$. Obrigado ao exílio voluntário, foi antes para Marselha depois para Malta e Constantinopla, onde implantou uma profícua atividade comercial. Em 1847, durante uma viagem à França e Inglaterra, conheceu Mazzini, ao qual permaneceu sempre devoto, a ponto de ser um dos poucos discípulos fiéis que em 1872 velaram o Apóstolo em Pisa em suas últimas horas de vida. Lemmi recebeu de Mazzini, em Abril de 1849, ordem para se dirigir a Livorno para embarcar a legião Manara que acorria em defesa da cidade. Depois da queda a República romana, voltou para Constantinopla.

Em 1851, sempre por encargo de Mazzini, fez contato com Lajos Kossuth, expatriado na fortaleza de Kütahja, e o ajudou a fugir, acompanhando-o depois em uma longa viagem a Londres e aos Estados Unidos. Voltando para Constantinopla em 1853, atendeu de novo ao apelo de Mazzini, empenhado na preparação do motim de 6 de Fevereiro. Preso em Gênova, mas logo solto pela intervenção do cônsul dos Estados Unidos, uma vez que era considerado cidadão norte-americano, em Março de 1853 refugiou-se na Suíça e de lá retomou o caminho de Constantinopla, onde permaneceu por muitos anos dedicando-se principalmente a seus negócios e acumulando uma notável fortuna. Foram as riquezas acumulada que lhe consentiram, em 1857, financiar a expedição de Carlo Pisacane e contribuir para o desenvolvimento do movimento patriótico de inspiração democrática, ganhando o apelido, dado por Giuseppe Guerzoni, de "banqueiro da revolução italiana".

Em 1860, voltou definitivamente para Itália, onde fez parte da organização da Expedição dos Mil e investiu algum capital na atividade ferroviária. Juntamente com o financista livornense e seu parente Pietro Antonio Adami, em Março de 1860, obteve do governo sardo o encargo de construir as linhas ferroviárias de Arezzo até a fronteira com o Estado Pontifício e de Florença a Ravena. Em 25

\footnotetext{
${ }^{576}$ Para referências bio-bibliográficas mais precisas recomendo o verbete "Adriano Lemmi" que redigi para o Dizionario biografico degli italiani. vol. 64. Roma: Istituto della Enciclopedia Italiana, 2005, pp. 345-348.
} 
de Setembro de 1860, Garibaldi confiou à empresa de Lemmi e Adami a construção de toda a rede ferroviária Meridional, continental e da Sicília, causando a preocupada reação dos moderados piemonteses, que com um novo contrato, de Abril de 1861, limitaram a esfera de ação da empresa, então denominada Sociedade Itálica Meridional, e chamaram para participar dela outros grupos financeiros setentrionais.

A partir desse momento, as relações de Lemmi com Garibaldi e com os outros expoentes do movimento democrático tornaram-se muito estreitas. Aliás, ele representou uma espécie de trait-d'union entre a ala republicana intransigente, tanto mazziniana quanto cattaneana, e a componente de mais direta matriz garibaldina, pronta a sacrificar a prejudicial institucional para completar a unificação do País e realizar um programa de reformas sociais e políticas. Assim, em Dezembro de 1863, ele esteve, com Garibaldi, Benedetto Cairoli, Giovanni Nicotera e outros, entre os que assinaram o ato constitutivo do Comitê Central Unitário, órgão criado pelos democratas para promover uma sublevação popular contra a Áustria, que em 1864 deveria terminar com a libertação de Veneza. Em 1864, participou da tentativa de Francesco Crispi e Antonio Mordini de criar uma ala intermediária entre a esquerda parlamentar e a extrema republicana, que mais adiante ganharia mais consistência no projeto intitulado "terceiro partido". Em 1879, financiou o surgimento do jornal La Lega della Democrazia (A Liga da Democracia), que deveria ter se transformado, segundo indicação de Garibaldi, no instrumento de união das forças esparsas da esquerda Democrática italiana. Ele já era um dos expoentes mais respeitáveis deste movimento, o que foi confirmado, em Maio de 1881, por sua assinatura no manifesto pela democracia francesa, redigido por Aurelio Saffi em forma de carta a Victor Hugo, para protestar contra a ocupação da Tunísia. Malograda a experiência da Liga, em Agosto de 1883 esteve entre os promotores do Fascio da Democracia, mais uma tentativa de conjugar as aspirações de radicais e republicanos e reuni-los em uma única estrutura organizacional.

A última parte da vida de Lemmi foi, entertanto, caracterizada por sua adesão à Maçonaria, na qual chegou em breve tempo a ocupar os maiores cargos de direção. Iniciado em Março de 1877, na loja Propaganda Maçônica, uma loja especial do Grande Oriente da Itália que reunia os membros do establishment político, econômico e cultural do País, foi logo chamado para fazer parte da 
comissão financeira da Obediência e apenas dois anos depois, em Maio de 1879, foi eleito grão-tesoureiro da ordem. Após ter ganho o favor de numerosas lojas, às quais garantiu a sobrevivência quitando com o próprio dinheiro as dívidas que estas tinham com o Grande Oriente, determinou para a inscrição de novos filiados, em Julho de 1880, uma taxa no valor de 100 liras que os liberaria definitivamente do pagamento das quotas anuais. Tratou-se de uma providência, imposta inicialmente como voluntária e tornada obrigatória em 1887, que visava por um lado selecionar o acesso à Maçonaria, abrindo-o para as classes sociais médio-altas e impedindo-o às classes populares, de outro, dotá-la de recursos econômicos indispensáveis para desenvolver um papel mais incisivo na vida pública do País.

A reforma de 1880 correspondia plenamente à exigência de dotar a sociedade de recursos financeiros necessários para se reforçar e poder desempenhar o papel público que Lemmi tinha em mente. Ele pensava que somente uma organização sólida e bem estruturada, homogênea sob o ponto de vista da extração social dos afiliados, poderia sustentar o confronto com a Igreja Católica, substituir a falta de um partido liberal moderno, defender as instituições nascidas com o Ressurgimento da dupla ameaça dos vermelhos e dos negros, o socialismo revolucionário e o clericalismo legitimista, apoiar a modernização do País em senso laico e democrático. O certo é que, se pensarmos que o salário médio diário de um operário raramente chegava a duas liras, fica evidente que um dos objetivos da reforma era exatamente "agregar os inscritos segundo critérios de classe"

Com as novas constituições de 1887, o grão-mestre também recebeu a atribuição da última e indiscutível aprovação para a admissão de novos irmãos. Assim com estava fazendo no plano político Crispi, que foi amigo íntimo de Lemmi, também o grão-mestre livornense concentrou em suas mãos um grande poder. De forma que algumas lojas, especialmente da Itália setentrional, lamentaram a instauração de sua parte de critérios de gestão pessoais e ditatoriais. E alimentaram uma oposição que no fim de 1895, em perfeita sincronia com a saída da cena política de Crispi, obrigou Lemmi a se demitir. Até então, todavia, ele governou a Maçonaria italiana com grande autoridade, servindo-se habilmente dos mais diversos recursos: do contato direto com a base, cultivado

\footnotetext{
${ }^{577}$ CORDOVA, F. - Maçonaria e politica in Italia, 1892-1908. Roma-Bari: Laterza, 1985, p. 2.
} 
mediante inúmeras viagens pela Itália, até grandes mobilizações públicas, como a de 1889 para a execução do monumento a Giordano Bruno em Campo de Fiori e a habilidade de fazer campanhas de imprensa bem organizadas. Entre estes meios estava o frequente recurso, em seus escritos aos irmãos, de fórmulas de sabor quase solene, que visavam fortalecer a componente "religiosa" do vínculo maçônico e pareciam, por outro lado, aos olhos de certa publicidade clerical, uma clara confirmação de sua inspiração satânica.

Entretanto, não há dúvida de que ele teve o mérito indiscutível de revitalizar a asfixiante organização maçônica, completando a obra de unificação iniciada pelos seus predecessores e principalmente tornando-a uma dinâmica protagonista da vida pública nacional. Depois de anos de lutas internas e uma existência praticamente incolor, a Maçonaria italiana teve finalmente um núcleo dirigente que soube dotá-la de um sólido quadro de referência ideológico e de uma estratégia política de amplo respiro: defesa das instituições, laicização do Estado (separação entre Estado e Igreja, introdução do divórcio, limites para o ensino religioso nas escolas), democratização do País através de um processo de reformas sociais e políticas graduais. Não por acaso, o articulado projeto de reforma concebido por Lemmi, que em alguns aspectos acabou coincidindo com o de Crispi, obteve o apoio de eminentes figuras do movimento republicano, como Aurelio Saffi e Giovanni Bovio.

Lemmi, em resumo, imprimiu uma mudança decisiva na fisionomia e nas atitudes do Grande Oriente, que foi cada vez mais configurando-se como um tipo de "superpartido" da burguesia italiana, como um dos mais importantes centros de elaboração e reunião das estratégias políticas da classe dirigente do País. "A Maçonaria - escreveu em 1889 - sem descer e se depreciar nas mesquinhas lutas da política cotidiana, deve participar dos grandes movimentos da Nação. Ou nós somos os inspiradores e moderadores da opinião pública, ou não temos razão séria para existir"s78.

Adriano Lemmi morreu em Florença em 23 de Março de 1906. Em extrema coerência com os ideais com os quais havia vivido, ele escolheu ser cremado. Nessa escolha, tão evocativa de precisos pertencimentos culturais e políticos, creio que

\footnotetext{
${ }^{578}$ Retiro a citação de uma circular de Lemmi, de 20 de Janeiro de1889, citada em CONTI, F. - Storia della massoneria italiana, op. cit., p. 126.
} 
se possa identificar um último traço de sua ligação com Livorno. De fato, não deixa de ser significativo que enquanto em outros lugares o rito da incineração dos cadáveres encontrava fortes resistências na opinião pública e nos setores mais tradicionais da classe dirigente, em Livorno, naqueles anos, existissem duas empresas para cremação que concorriam entre si. Exatamente no período entre o início de 1900 e os primeiros anos do fascismo, houve ali um número de cremações muito mais elevado do que em todas as cidades italianas ${ }^{579}$.

Cremação e honras fúnebres civis talvez significassem a manifestação mais extrema de uma visão laica da existência (e da morte), eram o testemunho de uma fé positivista na ideia de modernidade e progresso, representavam parte essencial da tentativa de elaborar uma religiosidade laica para contrapor à católica. Em última instância, pretendiam afirmar a vontade de defender o valor do livre arbítrio, os direitos invioláveis do indivíduo, a própria essência do Estado liberal que saíra das lutas pelo Ressurgimento. Para o sucesso desses princípios, Adriano Lemmi havia sacrificado boa parte de sua vida, às vezes beirando um aceso anticlericalismo. Até sob este último aspecto, as ligações com sua Livorno permaneceram viscerais e profundas.

\footnotetext{
579 Cfr. SONETTI, C. - Una morte irriverente. La Società di Cremazione e l'anticlericalismo a Livorno. Bolonha: Il Mulino, 2007.
} 